\author{
Jan J. De Waele \\ F. Berrevoet \\ K. Reyntjens \\ P. Pletinckx \\ I. De laet \\ E. Hoste
}

\section{Semicontinuous intra-abdominal pressure measurement using an intragastric Compliance catheter}

Received: 1 March 2006

Accepted: 4 April 2007

Published online: 24 May 2007

(C) Springer-Verlag 2007

Electronic supplementary material

The online version of this article (doi:10.1007/s00134-007-0682-3) contains supplementary material, which is available to authorized users.

J.J. De Waele is supported by a Clinical Doctoral Grant of the Fund for Scientific Research-Flanders (Belgium;

F.W.O.-Vlaanderen).

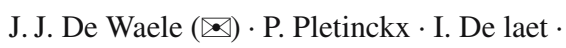
E. Hoste

Ghent University Hospital, Intensive Care Unit,

De Pintelaan 185, 9000 Gent, Belgium

e-mail: jan.dewaele@UGent.be

Tel.: +32-92-402775

Fax: +32-92-404995
F. Berrevoet

Ghent University Hospital, Department of

Anesthesiology,

De Pintelaan 185, 9000 Ghent, Belgium

K. Reyntjens

Ghent University Hospital, Department of Surgery,

De Pintelaan 185, 9000 Ghent, Belgium

\begin{abstract}
Objective: To compare intra-abdominal pressure (IAP) measurements obtained from an intragastric Compliance catheter with the pressure measured directly in the abdominal cavity. Design and setting: Prospective cohort study in an operating room of the Ghent University Hospital Patients: Seven patients undergoing elective laparoscopic cholecystectomy. In-
\end{abstract}

terventions: IAP was obtained from both an intragastric catheter and directly from the peritoneal cavity at 1-minute intervals in patients undergoing elective cholecystectomy and compared using Bland-Altman analysis. Measurements and results: In 156 paired measurements obtained from 7 patients the mean difference between IAP $_{\text {gastric }}$ and IAP $_{\text {ref }}$ was $0.12 \pm 0.70 \mathrm{mmHg}(95 \%$ CI 0.01-0.23). Conclusions: IAP measured using an intragastric Compliance catheter reliably reflects the reference IAP in patients undergoing laparoscopic cholecystectomy.

Keywords Intra-abdominal pressure $\cdot$ Intra-abdominal hypertension $\cdot$ Abdominal compartment syndrome $\cdot$ Surgery $\cdot$ Trauma Critically ill patients

\section{Introduction}

In critically ill patients, intra-abdominal hypertension (IAH) and abdominal compartment syndrome are increasingly appreciated [1] and intra-abdominal pressure (IAP) monitoring is becoming routine in these patients. Several techniques have been described for the measurement of IAP. Currently the transvesical route remains the most popular one [2]. The use of an intragastric balloon catheter may be an interesting alternative for the transvesical route as it makes continuous IAP measurement possible. Previously we found in a laboratory experiment that a balloon-tipped catheter filled with 1-3 ml air accurately transduces pressures [3]. Other balloon-tipped catheters have been reported to give reliable and reproducible IAP measurements [4, 5]. During laparoscopic procedures IAP is maintained at $10-15 \mathrm{mmHg}$ using carbon dioxide to create a pneumoperitoneum. The pressure is set at a predefined level and remains constant. Because the pressure is constant during a laparoscopic procedure this 
creates an ideal setting for evaluating new devices for IAP measurement. In addition, the reference pressure is easily measured and the IAP during a laparoscopic procedure usually is at a clinically relevant level $(10-20 \mathrm{mmHg}$. Several studies evaluating methods for IAP measurement have been performed using this setup [6-9].

This study compared pressure measurements obtained from an intragastric Compliance catheter with the pressure measured directly in the abdominal cavity during laparoscopic cholecystectomy. Findings have been presented previously at the annual meeting of the European Society of Intensive Care Medicine in Amsterdam, 10-13 October 2005.

\section{Methods}

The study included seven patients undergoing elective laparoscopic cholecystectomy (four men, 3 women; mean age 46 years). It was conducted in the operating theater of Ghent University Hospital and was approved by the hospital's ethics committee; written informed consent was obtained from the patients before the operation.

After induction of anesthesia a Compliance catheter (International Medical Systems, Zutphen, The Netherlands; Fig. 1) was introduced under direct vision in the esophagus and into the stomach. The balloon was filled with $3 \mathrm{ml}$ air, and the catheter was attached to a pressure transducer connected to the patient monitoring system. After the pneumoperitoneum was established, a rigid pressure line was connected to one of the laparoscopic ports in direct connection with the peritoneal space. This pressure line was also connected to a transducer and recorded the reference pressure $\left(\mathrm{IAP}_{\text {ref }}\right)$. The position of the balloon was checked by comparing the pressure tracings from the

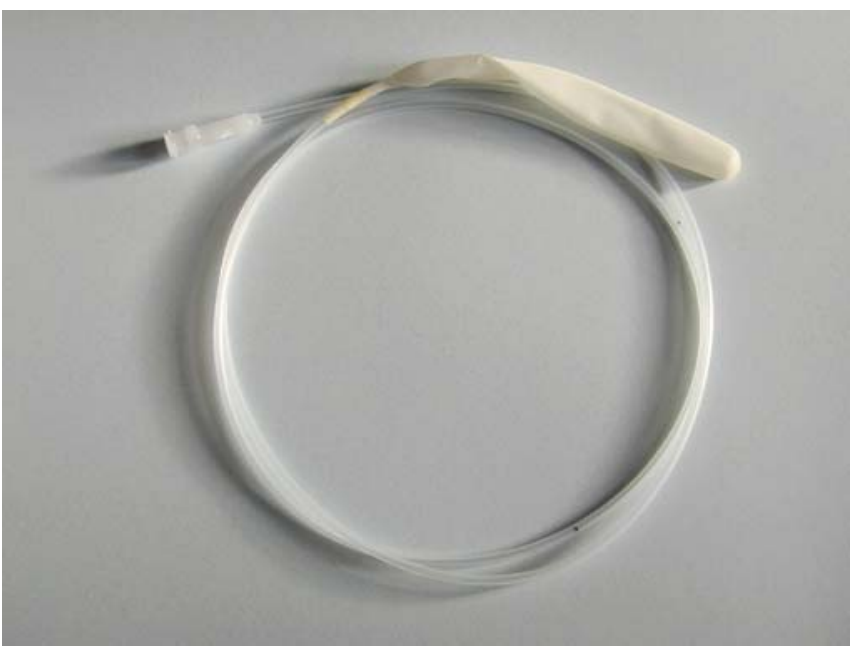

Fig. 1 Compliance catheter (International Medical Systems, Zutphen, The Netherlands) two pressure lines and by manipulation of the stomach by the surgeon. Pressures from both pressure lines were obtained at 1-min intervals except during periods of insufflation of $\mathrm{CO}_{2}$ into the abdomen, as this caused substantial fluctuations in IAP. When the gallbladder was extracted from the abdomen, the measurements were stopped. A total of 156 paired measurements were obtained from the seven patients; for each patient between 16 and 27 paired measurements were available for analysis (median 24). The $\mathrm{IAP}_{\text {ref }}$ ranged from 6 to $18 \mathrm{mmHg}$.

The pressure obtained from the Compliance catheter $\left(\mathrm{IAP}_{\text {gastric }}\right)$ and the $\mathrm{IAP}_{\text {ref }}$ (the pressure directly measured in the abdominal cavity) were compared using Bland and Altman [10] analysis. The mean $\pm \mathrm{SD}$ difference between $\mathrm{IAP}_{\text {gastric }}$ and $\mathrm{IAP}_{\text {ref }}$ was calculated, including a $95 \%$ confidence interval $(\mathrm{CI})$. We considered the balloon to be acceptable for clinical use if the mean difference was $1 \mathrm{mmHg}$ or less, and if the standard deviation was lower than $1 \mathrm{mmHg}$. Analyses were carried out using Medcalc 8.1 (Medcalc, Mariakerke, Belgium). Differences at the level of $p \leq 0.05$ were considered statistically significant.

\section{Results}

The mean overall difference between $\mathrm{IAP}_{\text {gastric }}$ and $\mathrm{IAP}_{\text {ref }}$ was $0.12 \pm 0.70 \mathrm{mmHg}$ (95\% CI $0.01-0.23$; Fig. 2 ). There was no evidence of bias at the extremes of the pressure range studied. In individual patients the mean difference was also within acceptable limits: the mean difference ranged from -0.48 to $0.63 \mathrm{mmHg}$ and $\mathrm{SD}$ from 0 to $0.99 \mathrm{mmHg}$ (Table 1). No clinical complications related to the introduction of the pressure catheter were seen.

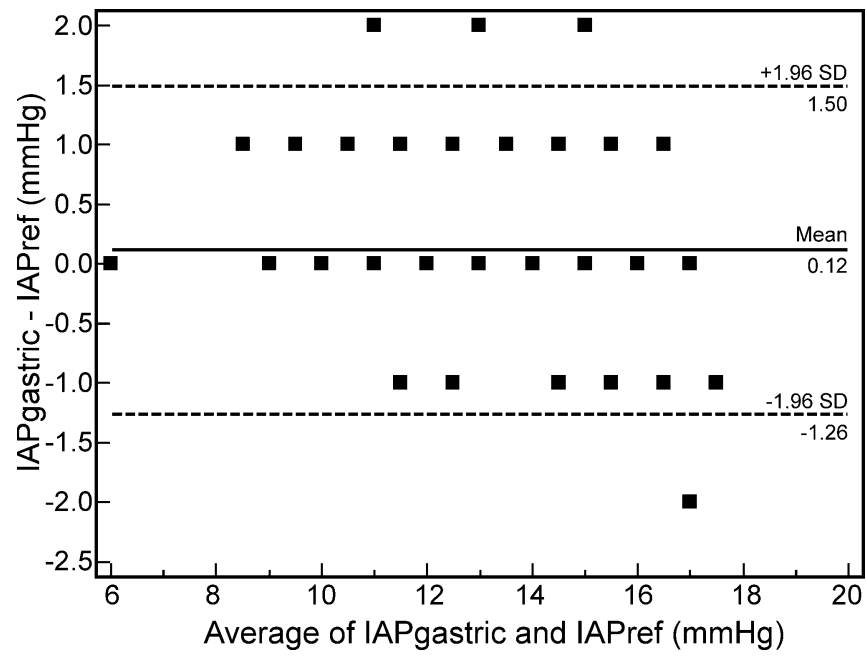

Fig. 2 Relationship between intra-abdominal pressure obtained from an intragastric Compliance catheter $\left(I A P_{\text {gastric }}\right)$ and reference intraabdominal pressure $\left(I A P_{r e f}\right)$ 
Table 1 Overview of the mean difference and standard deviation in individual patients

\begin{tabular}{clcl}
\hline Patient no. & Number of measurements obtained & Mean difference $(\mathrm{mmHg})$ & Standard deviation $(\mathrm{mmHg})$ \\
\hline 1 & 25 & 0 & 0.65 \\
2 & 24 & 0.12 & 0.99 \\
3 & 27 & 0.63 & 0.63 \\
4 & 16 & 0.13 & 0.34 \\
5 & 17 & 0.53 & 0.51 \\
6 & 22 & 0 & 0 \\
7 & 25 & -0.48 & 0.59 \\
\hline
\end{tabular}

\section{Discussion}

This study found that the intragastric Compliance catheter accurately measures IAP and therefore is a potential alternative to other available methods for continuous IAP measurement. The mean difference between IAP measured using the intragastric Compliance catheter and that measured directly was $0.12 \mathrm{mmHg}$, was well within the limits determined before starting the experiment. Continuous IAP measurement seems advisable in selected critically ill patients as there is evidence that IAP may fluctuate considerably over time. This requires frequent measurements by the nursing staff, which is time consuming in often critically ill patients. Apart from this the abdominal perfusion pressure (mean arterial pressure minus IAP) has been proposed as a potential target for resuscitation. The use of this parameter as a target also obviates the need for continuous IAP assessment.

Balloon tipped catheters have been tested before, both in vitro [4] and in vivo [5], and have been found to be easy to use. IAP values obtained through these catheters are highly reproducible and seem to be a promising technique for continuous or semicontinuous IAP measurement. Also other techniques for continuous have been introduced: Balogh et al. [11] reported their experience with an elegant system for continuous IAP measurement using the transvesical route and found this technique to be very reliable. The use of the transgastric route for IAP measurement is not new. A laboratory experiment found the intragastric pressure to be well correlated with the pressure measured directly in the abdomen [12], a finding confirmed in another laboratory setting using this specific setup [3]. The transgastric route has also been used to measure the IAP in critically ill patients [13], and several automated techniques have recently become commercially available.

The advantages of using an intragastric Compliance catheter in critically ill patients are numerous. First, the catheter can be connected to the monitoring equipment used in the unit, solving the problem of the availability of a limited number of dedicated devices. The catheter is relatively cheap ( $€ 12$, approx. US \$14) and easy to use. It overcomes the problem of overestimation of IAP when using transvesical techniques in patients with compartment syndrome limited to the pelvis in localized hematomas, and it provides a method for IAP measurement in patients without bladder catheters. Possible drawbacks are the need for an additional catheter and the possible interference with peristalsis, medication, and enteral nutrition. These issues should be addressed when studying the clinical applicability in ICU patients.

In conclusion, IAP measured using an intragastric Compliance catheter reliably reflects the reference IAP in patients undergoing laparoscopic cholecystectomy and is an alternative for continuous IAP measurement in patients at risk for IAH.

\section{References}

1. Malbrain ML, Chiumello D, Pelosi P, Wilmer A, Brienza N, Malcangi V, Bihari D, Innes R, Cohen J, Singer P, Japiassu A, Kurtop E, De Keulenaer BL, Daelemans R, Del Turco M, Cosimini P, Ranieri M, Jacquet L, Laterre PF, Gattinoni L (2004) Prevalence of intra-abdominal hypertension in critically ill patients: a multicentre epidemiological study. Intensive Care Med 30:822-829
2. Malbrain ML (2004) Different techniques to measure intra-abdominal pressure (IAP): time for a critical re-appraisal. Intensive Care Med 30:357-371

3. De Waele JJ, Billiet EA, Hoste E, Blot SI, Colardyn FA (2005) Fluid vs. air for semicontinuous intra-abdominal pressure measurements using a compliance catheter. Intensive Care Med 31:598-599
4. De Potter TJ, Dits H, Malbrain ML (2005) Intra- and interobserver variability during in vitro validation of two novel methods for intra-abdominal pressure monitoring. Intensive Care Med 31:747-751 
5. Schachtrupp A, Tons C, Fackeldey V, Hoer J, Reinges M, Schumpelick V (2003) Evaluation of two novel methods for the direct and continuous measurement of the intra-abdominal pressure in a porcine model. Intensive Care Med 29:1605-1608

6. Brooks AJ, Simpson A, Delbridge M, Beckingham IJ, Girling KJ (2005)

Validation of direct intraabdominal pressure measurement using a continuous indwelling compartment pressure monitor. J Trauma 58:830-832

7. Fusco MA, Martin RS, Chang MC (2001) Estimation of intra-abdominal pressure by bladder pressure measurement: validity and methodology. J Trauma 50:297-302
8. Sugrue M, Buist MD, Lee A, Sanchez DJ, Hillman KM (1994) Intra-abdominal pressure measurement using a modified nasogastric tube: description and validation of a new technique. Intensive Care Med 20:588-590

9. Johna S, Taylor E, Brown C, Zimmerman G (1999) Abdominal compartment syndrome: does intra-cystic pressure reflect actual intra-abdominal pressure? A prospective study in surgical patients. Crit Care (Lond) 3:135-138

10. Bland JM, Altman DG (1986) Statistical methods for assessing agreement between two methods of clinical measurement. Lancet I:307-410
11. Balogh Z, Jones F, D'Amours S, Parr M, Sugrue M (2004) Continuous intra-abdominal pressure measurement technique. Am J Surg 188:679-684

12. Engum SA, Kogon B, Jensen E, Isch J, Balanoff C, Grosfeld JL (2002) Gastric tonometry and direct intraabdominal pressure monitoring in abdominal compartment syndrome. J Pediatr Surg 37:214-218

13. Collee GG, Lomax DM, Ferguson C, Hanson GC (1993) Bedside measurement of intra-abdominal pressure (IAP) via an indwelling naso-gastric tube: clinical validation of the technique. Intensive Care Med 19:478-480 